\title{
Routes to Writing in Southern Africa
}

Brenda Leibowitz and Yasien Mohamed. Cape Town, South Africa: Silk Road International Publishers, 2001. p. 285. ISBN 1-875047-050

Writing is certainly one of man's greatest inventions, and good writing is a skill which elevates one's position in the society of the leamed. The other side of the coin is poor writing that leads to poor communication and often miscommunication between the writer and the reader(s). Writing in the academic world is all the more important, as it is the only means of scholarly expression. The quality of good writing skills is a cause of concem for many teachers at various stages of education, especially at the tertiary level. This is perhaps more true of students whose native language is not English, and for lecturers who have to teach such students.

The book under review is a collection of essays written by lecturers and writing specialists primarily at the University of Westem Cape (UWC). It is divided into six major parts and fourteen chapters. The essays are written on various themes that provide guidelines for developing writing skills in the academic setting. The book is edited by Brenda Leibowitz, Director of the National Center for Curriculum Research and Development at the Department of Education, and Yasien Mohamed, a senior lecturer in the Department of Foreign Languages at UWC.

The editors have compiled this book with the aim of providing insight, reflection, and guidelines that would empower lecturers to teach their subject more effectively and especially to help students with the writing aspect of their university study. Mohamed, who wrote the introduction to the book, comments that writing and its development should be viewed as a "humanistic" activity, which recognizes the natural and creative forms of personal narrative writing, as opposed to a scientific approach, where writing is viewed as a product rather than a process. Actually, this empathetic approach to writing development is evident throughout the book.

Part I of the book consists of one chapter only and deals with the importance of writing and teaching in the academia, emphasizing the need for lecturers to be evaluative of their own writing practices. Basing the advice on many years of experience as a trainer of writing, the author suggests many useful writing strategies including the use of dialogic materials, mind mapping, free writing, and writer's support groups.

Part II deals with diversity, culture, and writing, and consists of chapters 
2 and 3. Chapter 2 emphasizes the role of culture in language learning. The author here makes a distinction between primary discourse. Primary discourse "includes everyday conversational interaction and demands no degree of specialized knowledge or language to participate in". "A secondary discourse is specialist discourse. It requires a degree of expert knowledge and language to produce and comprehend it-something that is, in rather simplistic terms, learned and refined rather than acquired." The author states that secondary discourse is a powerful way of expression and today's student needs this power. However, in facilitating access to this kind of communication, teachers must take into account student background not as a barrier but as a resource for learning. This practice, the author contends, gives students a sense of who they presently are and who they are supposed to be at the tertiary level. The author also suggests how students can make the transition of communication from primary to secondary or academic levels of discourse. It is pointed out that students should be viewed as different from one another, as they represent unique cultural and language varieties. In chapter 3 , the author deals more with gender issues relating to academic discourses. Based upon interviews of college students, suggestion is made that teachers should consider "gender subjectivity" in written work so that students could reflect upon themselves as male or female writers, and urges that the personal touch should be present in all writings, including academic ones.

Part III addresses the theme dealing with "writing in the curriculum" and contains chapters 4,5 , and 6 . The authors here suggest that writing evaluation criteria should be explicit in order to make students aware of what to write and how to write it. The authors ask the teachers to be reflective of their methods of evaluation including personal and cultural factors, which might have a negative influence on grading practices. One author also documents a faculty survey at UWC conducted during 1995-97, which reflects the writing practices in fourteen academic departments. The survey shows different writing forms currently used and an opportunity for the writers to learn from others' styles. The chapters give a picture of the university context and self-examination on the part of the teachers. While chapter 4 deals specifically with writing policies and practices at UWC, chapter 5 addresses student assessment and its effect on student attitude towards quality of writing. It is pointed out that the problem teachers may have is in making distinctions between a conceptually strong but grammatically flawed piece of writing. The book discusses strategies to 
overcome this difficulty. Marking criteria, feedback specifics, marking sheets, peer editing, and self-assessment methods are carved out in a simple-to-understand manner. In chapter 6 , the author focuses on the techniques which can be used by the lecturer for improving students' writings. Emphasis is laid on the lecturers to focus on the content of the essay rather than its form. The lecturer should also consult with the Writing Center Specialist and together they should work on enhancing students' writing. Special emphasis is given to written feedback, including making the feedback comprehensible; prioritizing issues; giving positive feedback; avoiding marking drafts; and positioning the feedback effectively.

Part IV covers "accessing sources" that are addressed in chapters 7,8 , and 9. The authors point out that a student skilled in researching literature appropriate to the assignment has better chances of putting together a paper that is meaningful and perhaps even impressive. Chapters 7 and 8 aim to empower the student by identifying relevant materials and teaching how to express themselves in writing creatively. Discussion is made relevant to the UWC Arts materials package and UWC Info lit projects. Chapter 8 specifically deals with the issue of plagiarism and suggests that this problem lies deep within the culture of non-reading, and is perhaps reinforced by apartheid education in South Africa. The author questions whether the student is aware of what plagiarism means and if it is learned or is a sign of a struggle to compete. It is argued that plagiarism indicates difficulties of learning rather than a deliberate deception alone. Recommendations on understanding as well as eliminating plagiarism are given. Chapter 9 presents the basics of scholastic writing. The author attributes a lack of culture of critical discourse to apartheid education, under-qualified teachers, over-crowded schools, and shortage of textbooks. This chapter deals with the examples of bibliographical entries including primary and secondary sources and explains the various referencing styles currently in use. It also acknowledges the value of a uniform referencing system across various departments and emphasizes the need for original writing as opposed to second-hand ideas, or at least a writing that gives a fresh angle on an old topic.

Part V consists of chapters 10 through 13, addressing "teaching initiatives" and the methodology of writing based on the teacher's personal experiences. The approaches described in these chapters are mostly student-centered, and the emphasis is more on the whole person involved in research-based writing rather than on seeing it as a mechanical process. 
Suggestions for advanced level students are given every step of the way for writing graduate papers including dissertations. Guidelines are also given on how to avoid getting side-tracked in one's research and how to avail a positive supervisory relationship, both techniques which are crucial in completing one's master's or doctoral level thesis and remain major stumbling blocks for many students.

In an attempt to develop critical insight into learning, one of the authors suggest that students select texts that relate to their cultural background. Reading is identified as a key problem, as the student must comprehend the material before writing an essay. It is correctly pointed out that readers must be shown methods which allow them to interpret the texts cognitively, emotionally, and critically, as these lead to true comprehension. A simple yet important method recommended for English class is for the students to write three letters to each other and then analyze them thoroughly during tutorial classes, thereby critically and comparatively evaluating one's own style with others in the group. The use of computers in learning English or other foreign languages is also encouraged.

Part VI highlights "changing the scene" and offers narrative statements for literary development and institutional renewal with reference to reading and writing. While in the first part of the chapter, the author employs exploratory narratives on various academic issues, the second part deals with analytic style, reflecting upon the main issues addressed in the narratives and pointing out that developing good writing involves a very sophisticated and multi-pronged approach that takes time but can be achieved through practice.

A common thread running across all chapters is the genuine concern of the writers and their wish to enhance student-writing skills. The authors have used their invaluable experience to come up with suggestions for common writing problems in tertiary education. Indeed, Mohamed is correct in his estimation that the authors are empathetic in dealing with the writing problem of students. The book presents an index at the end, which the reader can find useful in locating areas of interest within the book. Although the book is a product of the South African experience, the problem of writing English exists in all universities where there are students whose native language is not English. This book is very useful for writing centers at universities, for departments of English, researchers in the field of linguistics and language methodology and most of all, for lecturers who are grappling with the problem of guiding students to write 
essays and research papers in the social sciences.

Amber Haque, Department of Psychology. Intemational Islamic Universily, Kuala Lumpur, Malaysia 